\title{
Degradation of human kininogens with the release of kinin peptides by extracellular proteinases of Candida spp.
}

\author{
Maria Rapala-Kozik', Justyna Karkowska-Kuleta' ${ }^{1}$, \\ Agnieszka Ryzanowska', Anna Golda', Anna \\ Barbasz $^{1}$, Alexander Faussner ${ }^{2}$ and Andrzej Kozik ${ }^{1, *}$ \\ ${ }^{1}$ Faculty of Biochemistry, Biophysics and Biotechnology, \\ Jagiellonian University, Gronostajowa 7, 30-387 Krakow, \\ Poland \\ ${ }^{2}$ Division of Clinical Chemistry and Clinical Biochemistry, \\ Ludwig-Maximilians-University, Nussbaumstrasse 20, \\ D-80336 Munich, Germany \\ * Corresponding author \\ e-mail: Andrzej.Kozik@uj.edu.pl
}

\begin{abstract}
The secretion of proteolytic enzymes by pathogenic microorganisms is one of the most successful strategies used by pathogens to colonize and infect the host organism. The extracellular microbial proteinases can seriously deregulate the homeostatic proteolytic cascades of the host, including the kinin-forming system, repeatedly reported to be activated during bacterial infection. The current study assigns a kininreleasing activity to secreted proteinases of Candida spp. yeasts, the major fungal pathogens of humans. Of several Candida species studied, $C$. parapsilosis and C. albicans in their invasive filamentous forms are shown to produce proteinases which most effectively degrade proteinaceous kinin precursors, the kininogens. These enzymes, classified as aspartyl proteinases, have the highest kininogen-degrading activity at low $\mathrm{pH}$ (approx. 3.5), but the associated production of bradykinin-related peptides from a small fraction of kininogen molecules is optimal at neutral $\mathrm{pH}$ (6.5). The peptides effectively interact with cellular B2-type kinin receptors. Moreover, kinin-related peptides capable of interacting with inflammation-induced B1-type receptors are also formed, but with a reversed $\mathrm{pH}$ dependence. The presented variability of the potential extracellular kinin production by secreted aspartyl proteinases of Candida spp. is consistent with the known adaptability of these opportunistic pathogens to different niches in the host organism.
\end{abstract}

Keywords: bradykinin; Candida albicans; Candida parapsilosis; candidiasis; des-arginine-kallidin; kinin receptors; secreted aspartyl proteinases.

\section{Introduction}

The incidence of severe fungal diseases in human populations has been increasing over the past few decades and has recently become a serious medical problem. This is partially owing to a gradually growing number of immunocompromised individuals such as those following surgery, organ transplantation or cancer therapy who are specifically prone to fungal infections. Other factors that might favor the occurrence of mycoses include the use of broad-spectrum antimicrobial drugs or prophylactic antifungal therapy, resulting in acquired drug resistance by some pathogenic species and high mortality among infected patients (Richardson, 2005; Perfect and Casadevall, 2006; Karkowska-Kuleta et al., 2009). The major fungal pathogens to humans are yeasts of the genus Candida, predominantly $C$. albicans, which belongs to the normal endogenous host flora and commensally occurs in the gastrointestinal tract, oral cavity and vagina of healthy individuals, often causing superficial infections (Mavor et al., 2005). However, in patients whose immune defense mechanisms are weakened these fungi could cause deep-seated mycoses of almost all inner organs, fungemia and life-threatening systemic diseases (Dean and Burchard, 1998; Cheng et al., 2005).

Pathogenic microbes use diverse strategies to colonize and infect the host organism, one of the most effective relying on the secretion of numerous proteolytic enzymes by microbial cells (Potempa et al., 2000; Staib et al., 2000). Some pathogen proteinases act non-specifically and digest most host proteins to enable tissue colonization and to provide nutrients necessary for microbe proliferation. Others are more specific and interact with the host proteolytic regulatory cascades to evade the host defense or, by contrast, take some benefits from the activation of host defense mechanisms (Maeda and Yamamoto, 1996; Bergmann and Hammerschmidt, 2007). As a representative example, the kinin-generating cascade (the kininogen-kallikrein system), one of the major systems for the biochemical homeostasis of the human body, has repeatedly been reported to be activated upon bacterial infections (Herwald et al., 2003). Kinins are vasoactive peptides, which regulate many physiological processes but also act as universal mediators of inflammation (Colman and Schmaier, 1997; Kaplan et al., 2002). Although the increased kinin production at the sites of infection should primarily be thought of as a part of the host defense against invading pathogens (Tapper and Herwald, 2000), some kininexerted effects might be beneficial to pathogens, such as the vascular permeability enhancement which helps them to acquire necessary nutrients or to colonize the host tissues (Miyoshi et al., 2004; Imamura et al., 2005, 2007). Owing to that dual role, the kinin generation, if moderate and controllable, could be important for maintaining the host-pathogen equilibrium (Frick et al., 2007) but, when excessive, becomes an important pathogenicity factor in severe lifethreatening systemic diseases such as sepsis (Hack and Colman, 1999). 
Extracellular bacterial proteinases augment the kinin levels at the site of infection through a direct action on the host proteinaceous kinin precursors, the kininogens (Herwald et al., 1996; Maruo et al., 1998; Imamura et al., 2004, 2005, 2007 ) or by a proteolytic activation of zymogen forms of host proteinases of the kinin-forming cascade (Molla et al., 1989; Maruo et al., 1998; Mattsson et al., 2001). Only the latter mechanism has so far been suggested to operate during candidiasis because a purified secreted aspartyl proteinase of C. albicans (Sap) was shown to activate the coagulation factor XII (Kaminishi et al., 1990). Additionally, a microbial proteinase-independent activation of the host plasma kininforming system was recently suggested to proceed after adsorption of its proteinaceous components on Candida spp. cell walls (Rapala-Kozik et al., 2008; Karkowska-Kuleta et al., 2010), a mechanism also extensively characterized for numerous bacterial pathogens (Ben Nasr et al., 1995, 1997; Mattsson et al., 2001; Bengtson et al., 2006). However, a direct kininogenase activity of candidial proteinases has not yet been described. Therefore, in the current study we characterize a degradation of kininogens by proteinases secreted by cells of several Candida species and show that this degradation is partially 'productive', i.e., results in the formation of biologically active kinin-related peptides.

\section{Results}

In the current study we found that Candida fungi secreted proteinases which were able to degrade the human kininogen, both in its high-molecular mass (HK) and low-molecular mass (LK) form. This kininogen degradation was observed when the fungi were cultured to a filamentous form stage (germ tubes or hyphae) in several media (YPD, YPD supplemented with BSA, RPMI). Representative blots obtained after incubation of kininogens with supernatants from the cultures of several Candida spp. in YPD medium are presented in Figure 1. The kininogenase activity of proteinases released into the medium decreased in the order C. parapsilosis $>$ C. albicans $>$ C. tropicalis $\approx C$. krusei $>C$. glabrata. In the supernatant from $C$. parapsilosis culture, both HK and LK were nearly completely degraded to short SDS-PAGE-undetectable peptides. By contrast, C. glabrata seemed to be devoid of this activity because the extent of kininogen degradation was comparable to that in control samples. Qualitatively similar results were obtained when the culture medium contained BSA which is known to markedly enhance the secretion of proteinases by Candida fungi (data not shown).

The degradation of HK by supernatants from the cultures of germ tube forms of $C$. albicans and $C$. parapsilosis was also analyzed in the presence of standard inhibitors for the major classes of proteinases (Figure 2). Only pepstatin A, the inhibitor of aspartyl proteinases, was able to prevent the kininogen degradation almost completely, in contrast to the minor inhibitory effects of E-64, $o$-phenanthroline and PMSF. The optimal $\mathrm{pH}$ for the kininogenase activity released into the medium by Candida fungi was in the acidic range ( $\mathrm{pH} 3.5-4.5)$ although the kininogen degradation was significant up to $\mathrm{pH} 6.5$ (Figure 3, C. albicans example).

We also performed similar analyses of the degradation of kininogen in plasma upon incubation with Candida extracellular proteinases (data not shown). When plasma samples were diluted into a neutral buffer ( $\mathrm{pH}$ 6.5), the C. albicans proteinases caused a total cleavage of $\mathrm{HK}$ and this degradation was significantly inhibited by aprotinin (a kallikrein inhibitor) but not by pepstatin A. However, when the dilution was made into an acidic buffer ( $\mathrm{pH} 4.5)$, the HK degradation, albeit only partial (approx. 50\%), could only be prevented by pepstatin A.

Further experiments involved several tests of kinin-forming activity of extracellular proteinases of Candida fungi. First, kinin-related compounds were detected in peptide mixtures produced from kininogens incubated with the supernatants from Candida spp. cultures using an enzymelinked immunosorbent assay (ELISA) kit commonly applied for the determination of bradykinin in body fluids. As specified by the manufacturer (Peninsula-Bachem, San Carlos, CA, USA), this kit is specific for the five-amino acid Cterminal sequence of bradykinin with its $\mathrm{C}$-terminal arginine residue. As seen in Figure 4A, peptides with that structural
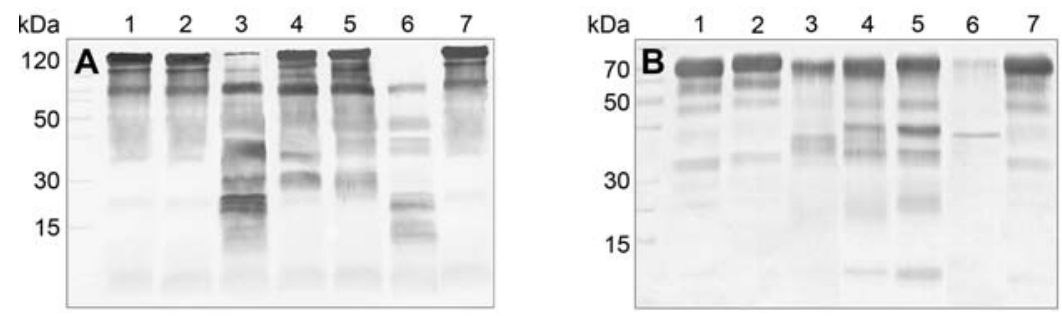

Figure 1 Western blot analysis of the degradation of human HK (A) or LK (B) by secreted proteinases of several Candida species. Candida spp. cells were grown in YPD medium at $37^{\circ} \mathrm{C}$ for $72 \mathrm{~h}$. After removing the yeasts by centrifugation, the proteinase-containing supernatants were concentrated by ultrafiltration. The supernatant samples were incubated with $\mathrm{HK}(2 \mu \mathrm{g})$ or LK $(1.8 \mu \mathrm{g})$ in $50 \mathrm{~mm}$ citrate buffer ( $\mathrm{pH} \mathrm{3.5)} \mathrm{for} 3 \mathrm{~h}$ at $37^{\circ} \mathrm{C}$, the protein fragments formed were separated by SDS-PAGE, transferred to a PVDF-membrane and probed by a primary antibody against HK or LK and an alkaline phosphatase-labeled secondary antibody. The protein bands were visualized with BICIP/NBT system. Lane 1, kininogen standard samples incubated in the buffer; lane 2, kininogens incubated in YPD medium; lanes 3-7: kininogens incubated with secreted proteinases of: C. albicans (3); C. krusei (4); C. tropicalis (5); C. parapsilosis (6) and C. glabrata (7). 


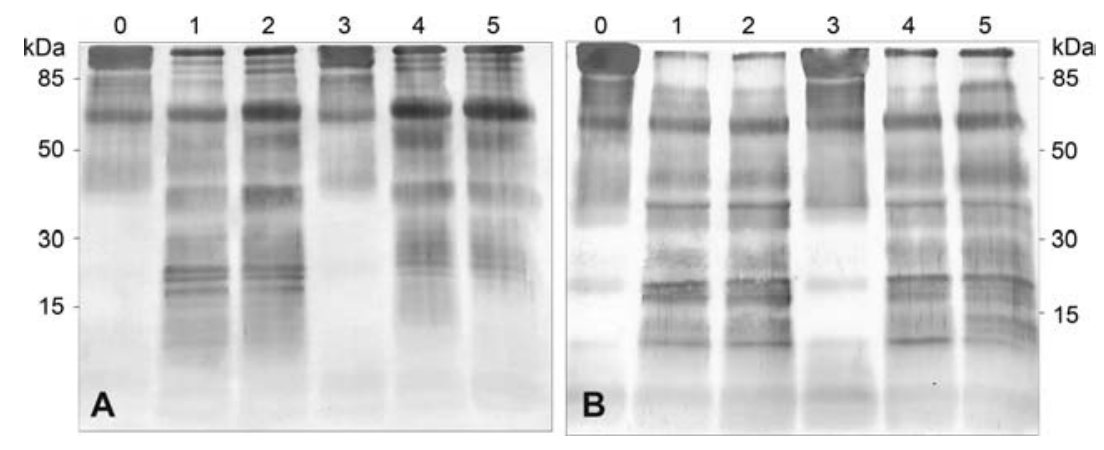

Figure 2 Effects of major proteinase class inhibitors on HK degradation by secreted proteinases of C. albicans (A) and C. parapsilosis (B).

The degradation procedure and its analysis were similar to that described for Figure 1 except that before HK addition the proteinase extracts were shortly $(10 \mathrm{~min})$ pre-incubated with selected inhibitors. In both $\mathrm{A}$ and $\mathrm{B}$, the lane 0 represents $\mathrm{HK}$ incubated in the buffer; lane 1 , HK degradation by proteinases without any enzyme pre-inhibition; lanes 2-5, the degradation of HK by Candida proteinases pre-incubated with $10 \mu \mathrm{M}$ E-64 (lane 2), $10 \mu \mathrm{M}$ pepstatin A (lane 3), $10 \mathrm{mM} o$-phenanthroline (lane 4) or $10 \mathrm{~mm}$ PMSF (lane 5).

feature were indeed produced, but the yield significantly depended on which of the two kininogens and which of the four Candida species were tested. The highest kinin production was recorded after the action of $C$. parapsilosis proteinases on LK, with the yield of approximately $35 \mathrm{ng} / \mathrm{ml}$ of incubation mixture which corresponds to less than $3 \%$ of kininogen molecules having been degraded toward these products. In this species, a three-fold lower amount of kinins was released from HK. In the three other species, the yield of kinin release was comparable among species when LK served as the substrate but gradually decreased when produced from $\mathrm{HK}$, in the order C. albicans $>C$. tropicalis $>C$. krusei. The $\mathrm{pH}$ dependence of kinin formation (Figure 4B) was opposite to that observed for kininogen degradation,

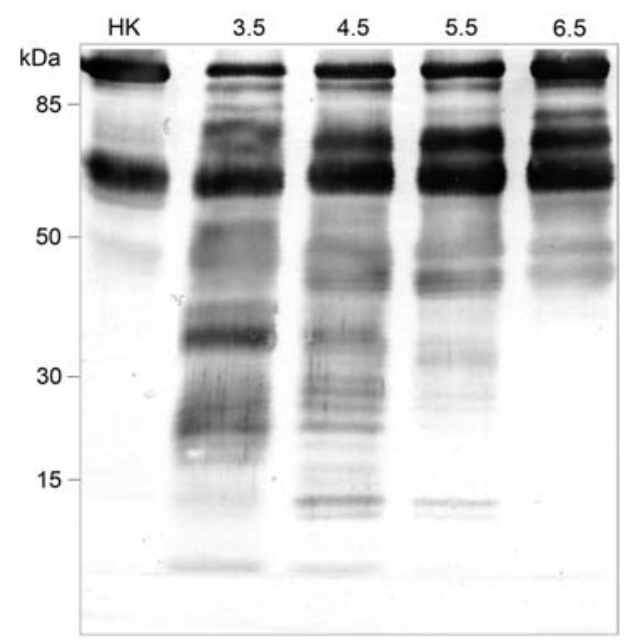

Figure $3 \mathrm{pH}$ dependence of the degradation of HK by C. albicans secreted proteinases.

Purified $\mathrm{HK}$ was incubated for $8 \mathrm{~h}$ at $37^{\circ} \mathrm{C}$ in $50 \mathrm{~mm}$ citrate buffer (pH 3.5 and 4.5) or $50 \mathrm{~mm}$ phosphate buffer ( $\mathrm{pH} 5.5$ and 6.6) with C. albicans proteinase sample $(14 \mu \mathrm{l})$ obtained as described above. Products of kininogen degradation were separated by SDS-PAGE, transferred to a PVDF-membrane and probed with the anti-HK antibody. with the amount of kinins released increasing five-fold between $\mathrm{pH} 4.5$ and 6.5 for $C$. albicans proteinases but only two-fold for $C$. parapsilosis. The kinin production was inhibited by pepstatin A - nearly completely at acidic $\mathrm{pH}$ and only by $60-70 \%$ at more neutral $\mathrm{pH}(6.5)$.

A preliminary chemical identification of the kinin-related peptides produced was performed by reversed-phase high performance liquid chromatography (RP-HPLC) of the proteolytically fragmented kininogens and the ELISA test for kinins in the fractions collected. Results obtained for HK digestion by $C$. parapsilosis proteinases are presented in Figure 5. The ELISA-positive peptides were eluted in a single but diffused peak with the retention time comparable to those of kallidin (lysyl-bradykinin) or bradykinin standards. These data suggest the production of one (or both) of the major kinins from kininogens under the action of the extracellular proteinases of Candida fungi.

Independently, we analyzed the interaction of cellular kinin-specific receptors with the kininogen fragments released by Candida proteinases. For that purpose we used a radioreceptor-assay in which the peptides of interest competed with tritium-labeled bradykinin for binding to HEK cells which stably express the B2 receptors on their surface (Figure 6A). These analyses were limited to the peptides generated by highly active proteinases of $C$. albicans and C. parapsilosis. In both cases, a B2 receptor-binding activity was detected which corresponded to that of bradykinin in nanomolar concentration range. Interestingly, this activity increased four- to ten-fold when the $\mathrm{pH}$ of the mixture in which the proteolytic reaction proceeded, changed from 4.5 to 6.5 .

We also checked a possibility that some of the peptides which were released from kininogens by Candida proteinases might interact with $\mathrm{B} 1$ receptors. Hence, a competitive radioreceptor-assay was performed with tritium-labeled des$\mathrm{Arg}^{10}{ }^{10}$-kallidin (DAKD) as the tracer ligand and HEK cells with over-expressed B1 receptors as the binders. We confirmed the production of such 'DAKD-related peptides' from kininogens by C. albicans and C. parapsilosis proteinases 

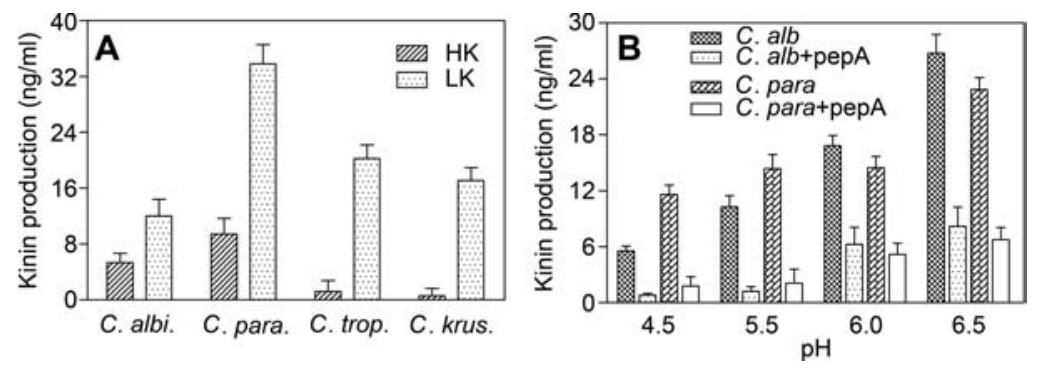

Figure 4 Production of kinin-related peptides from kininogens by secreted Candida spp. proteinases.

The kininogens were treated with Candida proteinases as described for Figure 1 and after stopping the proteolysis with pepstatin A, the samples were tested for kinin content by an ELISA method. (A) For proteinases of C. albicans and C. parapsilosis, the pH dependence of kinin production from HK was further analyzed (B) in the buffer systems described for Figure 3 . The production of kinins by proteinase extracts which were pre-incubated for $15 \mathrm{~min}$ with $10 \mu \mathrm{M}$ pepstatin A (pepA) is also shown.

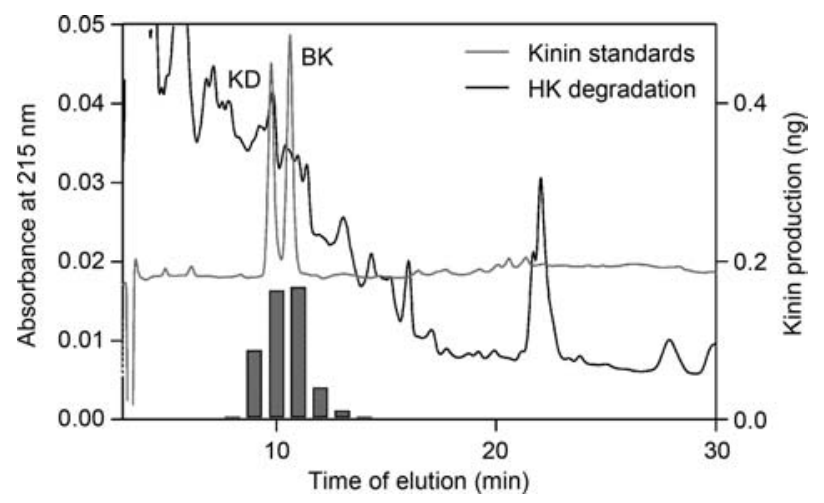

Figure 5 HPLC analysis of kinin generation from HK by secreted proteinases of $C$. parapsilosis.

The mixture of peptides, produced from HK degradation by $C$. parapsilosis proteinases, was separated on a Supelcosil LC-318 reversephase column with linear acetonitrile gradient elution and with spectrophotometric detection at $215 \mathrm{~nm}$ (black line). The eluted fractions $(1 \mathrm{ml})$ were colleted, lyophilized and analyzed by ELISA for kinin content (bars). A chromatogram from the separation of a kallidin (KD) and bradykinin (BK) standard mixture (gray line) is also shown.
(Figure 6B). In contrast to the B2 receptor-interacting peptides, the highest yield of DAKD-related kininogen fragments was observed when the $\mathrm{pH}$ of the proteolytic reaction mixture was acidic ( $\mathrm{pH} 4.5)$. When the proteolysis was performed at $\mathrm{pH} 6.5$, the yield of DAKD-related peptides dropped to nearly zero for C. albicans proteinases or to approximately $50 \%$ for $C$. parapsilosis enzymes. These findings suggest that the two types of kinin receptor ligands produced by Candida proteinases play alternating roles in environments with different acidity.

\section{Discussion}

The ability of Candida spp. cell walls to tightly bind all components of human kinin-forming systems was only recently discovered and characterized (Rapala-Kozik et al., 2008; Karkowska-Kuleta et al., 2010). Additionally, an actual release of kinins from HK, co-adsorbed with factor XII and prekallikrein was shown to proceed with a low yield. The phenomenon resembles that which normally occurs on
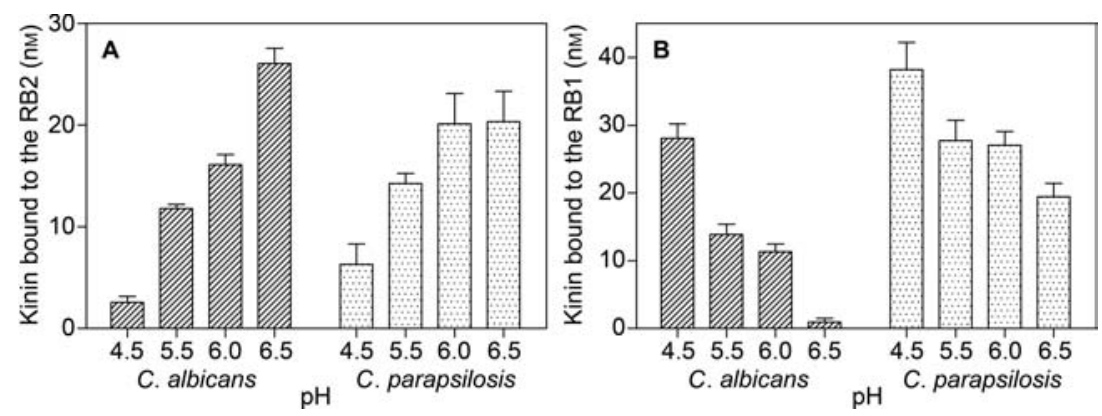

Figure 6 Cellular receptor-binding assays of kinin-related peptides produced by secreted proteinases of C. albicans and C. parapsilosis. HEK293 cell monolayers, stably expressing the human B2 (A) or B1 (B) kinin receptors, were used. In this competitive radioreceptor-assay, the cells were incubated with mixtures of $2 \mathrm{~nm}\left[{ }^{3} \mathrm{H}\right]$ bradykinin (A) or $1 \mathrm{~nm}\left[{ }^{3} \mathrm{H}\right] \mathrm{DAKD}$ (B) with the diluted samples of HK, degraded at different $\mathrm{pH}$ values (see Figure 3). After washing, the surface-bound $\left[{ }^{3} \mathrm{H}\right]$ radioactivity dissociated by acetic acid/ $\mathrm{NaCl}$ treatment was measured in a beta-counter. The amounts of bradykinin-related or DAKD-related peptides were estimated from calibration plots, prepared with bradykinin or DAKD standards. 
host cells (Joseph and Kaplan, 2005; Barbasz et al., 2008; Barbasz and Kozik, 2009) and could play a role in maintaining the host-pathogen equilibrium or in the pathogenesis of mild superficial candidial infections. Severe fungal infections of inner organs, candidemia or Candida-dependent sepsis are likely to involve more drastic kinin-generating factors such as proteinases secreted by Candida cells, particularly if they can act directly on kinin precursors, the kininogens.

In the current study, for the first time, the proteolytic cleavage of human kininogens by extracellular proteinases of Candida spp. has been characterized both in general terms of fragmentation of the entire kininogen molecule, as well as with respect to a more specific ability to form kinin-related peptides. The variation of the kininogen-fragmentation ('kininogenase') activity between several Candida species (Figure 1) did not match the one recently reported for the contact system adsorption capability (Rapala-Kozik et al., 2008). Candida parapsilosis secreted the proteinases which were most active against kininogens but its cell wall only moderately bound proteins of the contact system. Candida tropicalis represented the opposite situation whereas C. albicans seemed to be well equipped with both features which should lead to effective production of kinins at the site of infection.

The strong inhibition of fungal kininogen-fragmentation activities by pepstatin A (Figure 2) proved that Candida kininogenases belonged mainly to the aspartyl proteinases (Saps), in a consistency with the well-known predominant contribution of proteinases of that class to the extracellular proteolytic activity of these fungi (for recent reviews see Naglik et al., 2003, 2004). However, because the pepstatin A prevention of kininogen degradation was incomplete, a contribution of extracellular proteinases of other classes could not be excluded (Figure 2). Serine- or metalloproteinases were occasionally identified in some Candida species (Rodier et al., 1999; dos Santos et al., 2006) but their production depended on the medium composition and was strongly suppressed by albumin.

The $\mathrm{pH}$ dependence of extracellular kininogenase activity (Figure 3) additionally confirmed the major role of Saps in the kiningen degradation (Naglik et al., 2004). In the supernatants from $C$. albicans and $C$. parapsilosis cultures, used in the current studies, the predominant proteinases should be Sap 2 and Sapp2 isoenzymes, respectively (White and Agabian, 1995; Hrušková-Heidingsfeldová et al., 2009).

In complex biological samples such as plasma, the process of kininogen degradation by Candida proteinases might be much more complex. The complete cleavage of plasma HK under incubation with $C$. albicans proteinases at neutral $\mathrm{pH}$ should be assigned to the activation of the kinin-forming cascade (HK-prekallikrein-factor XII) of the host (Kaminishi et al., 1990) rather than to the direct action of fungal proteinases on the HK molecules. The latter mechanism could become predominant in the plasma exudates into the inflammatory foci with an acidic environment.

The major finding of the current study is the unequivocal evidence that during kininogen proteolysis by Candida Saps a fraction of kininogen molecules $(<5 \%)$ could be processed toward production of vasoactive and proinflammatory peptides - the kinins (Figure 4A). The $\mathrm{pH}$ dependence of this process (Figures 4B and 6A), particularly for C. albicans proteinases, was opposite to that for general kininogen fragmentation, suggesting that other proteinases with activity optima shifted to higher $\mathrm{pH}$ cooperated with the predominant Sap2 for the kinin production. As the major part of this kinin-forming activity at neutral $\mathrm{pH}$ was inhibited by pepstatin A, it could be assigned to the aspartyl proteinases, probably of the subset Sap4-6, which is known to be preferentially expressed during hyphae formation (Felk et al., 2002). However, only Sap3 shows a clear specificity toward arginine at the $\mathrm{P}_{1}$ position (Koelsch et al., 2000). Such a cleavage is necessary to release the $\mathrm{C}$-terminus required for the interaction with the antibodies contained in the 'bradykinin specific' ELISA kit or with cellular B2 kinin receptors. Hence, the pepstatin A-sensitive part of the kinin production might be owing to a minor-preference cleavage by Sap4-6 proteinases. The residual part, resistant to pepstatin A, could be assigned to the action of serine- or metalloproteinases (Rodier et al., 1999; dos Santos et al., 2006) which were likely to be present in trace amounts in the supernatants from the yeast culture.

We also showed that some peptides released from kininogens by the action of $C$. albicans and $C$. parapsilosis extracellular proteinases could interact with B1 kinin receptors (Figure 6). These receptors require that their ligands have a C-terminus as in DAKD which could be formed after the cleavage of $\mathrm{Phe}^{370}-\mathrm{Arg}^{371}$ bond in the kininogen sequence. The preference of $C$. albicans Saps 1, 2, 3 and 6 for $\mathrm{Phe}$ at $\mathrm{P}_{1}$ fulfills that requirement (Koelsch et al., 2000). Also, the $\mathrm{pH}$ dependence for the production of DAKD-related peptides is consistent with the activity optimum of the presumably predominant Sap2. The less sharp $\mathrm{pH}$ dependence of the production of $\mathrm{B} 1$ receptor ligands by $C$. parapsilosis agrees with the catalytic properties of Sapp2 (Hrušková-Heidingsfeldová et al., 2009).

Taken together, the current data suggest that the generation of proinflammatory kinin peptides could happen upon infection of human host by Candida fungi owing to the kininogenase activity of extracellular fungal proteinases. Infectious filamentous forms of the fungi secrete much higher amounts of proteinases than commensal yeast cells. The microbial proteinase-dependent kinin production might overwhelm the one which depends on the adsorption of host plasma contact system proteins on the fungal cell walls, with $C$. albicans being exceptional in having both mechanisms highly effective. However, the characteristics of fungal proteolysis of kininogens could differ between various niches of macroorganism (De Bernardis et al., 1998). One environmental factor that might regulate the profile of kinin generation is $\mathrm{pH}$. Hence, at the acidic $\mathrm{pH}$ of the human vagina which is normally approximately 4.5 but increases upon infections (Boskey et al., 1999) kininogens might be extensively degraded for fungal nutritional purposes but the type of bioactive kininogen-derived peptides (DAKD-related) is suitable for exciting B1 receptors which are engaged in chronic inflammatory reaction (Phagoo et al., 2005; Stadnicki et al., 2005). The 
higher $\mathrm{pH}$ known to promote the hyphal growth (Felk et al., 2002) enhances production of bradykinin-related kinins which exert their proinflammatory effects via B2 receptors, presented on the majority of host cells and involved in immediate inflammatory responses (Stadnicki et al., 2005). The low overall kininogen degradation and a relatively high production of true kinins should characterize candidial infections in niches with neutral $\mathrm{pH}$ such as oral cavity or gastrointestinal tract. However, the growing fungi acidify the medium (White and Agabian, 1995) which, according to our data, should result in a shift to the chronic inflammation state. As with many other reports, our work once again confirms the amazing adaptability of $C$. albicans and other Candida species to the conditions met at different host niches and in a variety of specific inflammation reactions.

\section{Materials and methods}

\section{Yeast strains and growth conditions}

The $C$. albicans ATCC 10231 strain was purchased from the American Type Culture Collection, the strains of C. glabrata, C. krusei, C. parapsilosis and C. tropicalis were provided by Dr. D. Trojanowska (Jagiellonian University, Medical College, Department of Pharmaceutical Microbiology, Krakow, Poland). Yeasts were grown at $37^{\circ} \mathrm{C}$ for $72 \mathrm{~h}$ in YPD buffered medium $(0.2 \%$ yeast extract, $0.2 \%$ peptone, $2 \%$ glucose, $\mathrm{pH}$ 6.5, obtained from Serva, Heidelberg, Germany), YPD medium supplemented with $0.2 \%$ BSA or RPMI medium (Sigma, St. Louis, MO, USA).

\section{Preparation and analysis of the mixtures of extracellular Candida proteinases}

After harvesting yeasts by centrifugation $(6000 \mathrm{~g}, 10 \mathrm{~min})$, the supernatant was concentrated ten-fold in an Amicon ultrafiltration chamber equipped with Ultracel YM membrane (10-kDa cut-off, Millipore, Billerica, MA, USA), dialyzed at $4^{\circ} \mathrm{C}$ for $24 \mathrm{~h}$ against $50 \mathrm{~mm}$ acetate buffer ( $\mathrm{pH} 6.0$ ), and stored at $-20^{\circ} \mathrm{C}$ for further analysis. The protein content in the supernatants from Candida spp. cultures in YPD and RPMI media was determined by the method of Bradford (1976). For the assay of proteolytic activities of the supernatants, hemoglobin degradation at $\mathrm{pH} 3.2$ was analyzed according to Anson (1938), with pepsin as the reference. The TCAsoluble products of hemoglobin degradation were detected after reaction with Folin-Ciocalteau reagent by measurement of optical density at $750 \mathrm{~nm}$ in a Power WaveX-Select microplate reader (Bio-Tek Instruments, Winoosky, VT, USA).

The SDS-PAGE pattern of the secreted Candida spp. proteinases was determined with the Laemmli system (Laemmli, 1970) using the reducing sample buffer and 10\% separating gel. After electrophoresis, protein bands were visualized by silver staining (Blum et al., 1987).

\section{Analysis of kininogen degradation}

HK (Enzyme Research Laboratories, South Bend, IN, USA) or LK (purified from human plasma according to the method of Johnson et al., 1987) (2 or $1.8 \mu \mathrm{g}$, respectively) was incubated with $14 \mu \mathrm{l}$ of Candida spp. proteinase extract in $50 \mathrm{~mm}$ citrate buffer $\mathrm{pH} 3.5$ (total volume of $20 \mu \mathrm{l}$ ) for $3 \mathrm{~h}$ at $37^{\circ} \mathrm{C}$. For the determination of $\mathrm{pH}$ dependence of kininogen proteolysis, $\mathrm{HK}$ was incubated for $8 \mathrm{~h}$ at $37^{\circ} \mathrm{C}$ in $50 \mathrm{~mm}$ citrate buffer $\mathrm{pH} 3.5$ and 4.5 or in $50 \mathrm{~mm}$ phosphate buffer $\mathrm{pH} 5.5$ and 6.5. Products of kininogen degradation were separated in the SDS-PAGE system described above, followed by the transfer onto polyvinylidene fluoride (PVDF) membrane (Immobilon; Millipore) for $40 \mathrm{~min}$ at $250 \mathrm{~mA}$ in $10 \mathrm{~mm}$ CAPS buffer $\mathrm{pH}$ 11 with $10 \%$ methanol (Matsudaira, 1987). The membrane was blocked overnight at $4^{\circ} \mathrm{C}$ in TTBS buffer $(1 \mathrm{~mm}$ Tris, $15 \mathrm{~mm} \mathrm{NaCl}$, $0.05 \%$ Tween 20, $\mathrm{pH} 7.6$ ) containing 5\% non-fat milk. After rinsing with TTBS buffer, the membrane was probed with primary antibodies against HK or LK (Acris, Herford, Germany) and secondary alkaline phosphatase-labeled antibody (Sigma). The protein bands were visualized with the BICIP/NBT system (Sigma).

\section{Analysis of proteinase classes involved in HK degradation by Candida spp.}

Extracts of proteinases secreted by C. albicans, C. krusei, C. tropicalis, and C. parapsilosis were first pre-incubated for $10 \mathrm{~min}$ at $37^{\circ} \mathrm{C}$ with one of the proteinase inhibitors: $10 \mu \mathrm{M}$ E- $64,10 \mu \mathrm{M}$ pepstatin A, $10 \mathrm{~mm} o$-phenanthroline or $10 \mathrm{~mm}$ PMSF at $\mathrm{pH} 3.5-6.5$. The HK degradation analysis was then performed as described above.

\section{HPLC analysis of kininogen degradation}

After 4-h incubation of HK or LK with Candida spp. proteinase extracts $(10 \mu \mathrm{g}$ of kininogen in $80 \mu \mathrm{l}$ total mixture volume, $\mathrm{pH}$ $3.5)$ at $37^{\circ} \mathrm{C}$, the reaction was stopped by adding $20 \mu \mathrm{l}$ of $2 \mathrm{M} \mathrm{HCl}$ and the sample was centrifuged at $10000 \mathrm{~g}$ for $10 \mathrm{~min}$, diluted three-fold with water and injected onto a RP-HPLC column Supelcosil LC-318, $5 \mu \mathrm{m}, 250 \mathrm{~mm} \times 4 \mathrm{~mm}$ (Supelco, Bellefonte, PA, USA). A binary solvent system was applied, with $0.1 \%$ trifluoroacetic acid (TFA, Sigma) in water as the solvent A and $0.08 \%$ TFA in $80 \%$ acetonitrile (HPLC gradient grade from Merck, Darmstadt, Germany) as the solvent B and with a gradient elution of $10-70 \%$ $\mathrm{B}$ in $40 \mathrm{~min}$ at a flow rate of $1 \mathrm{ml} / \mathrm{min}$. The eluted peptide fractions were collected, lyophilized and, after dilution, analyzed for the presence of kinins by ELISA (see below).

\section{Determination of kinins by ELISA}

This method for determination of bradykinin-like peptides was carried out using an ELISA kit (Peninsula Laboratories-Bachem, San Carlos, CA, USA), following the manufacturer's instructions. Briefly, a constant concentration of biotinylated bradykinin and various concentrations of sample kinins competed for binding to an antiserum, immobilized in a microplate well. The biotinylated tracer bound was quantified with streptavidin-conjugated horseradish peroxidase/3,3',5,5'-tetramethylbenzidine (SA-HRP/TMB) detection system (Sigma). A calibration curve was prepared in a bradykinin concentration range of $0-5 \mathrm{nM}$.

\section{Detection of kinin-like peptides by competitive kinin radioreceptor-assay}

HEK 293 cell lines with overexpressed kinin receptors The generation of the HEK 293 cells stably overexpressing the human B1 or B2 kinin receptor have been described before (Zubakova et al., 2008). Both cell lines have been obtained using the Flp-In TREx-system from Invitrogen (Carlsbad, CA, USA). The HEK 293 cells were cultivated in DMEM medium with high glucose, $2 \mathrm{~mm}$ glutamine, $10 \%$ fetal bovine serum and penicillin/streptomycin $(100 \mu \mathrm{g} / \mathrm{ml})$. Half of the used medium was replaced by fresh medi- 
um every 4 days. For binding experiments the cells were seeded in 96-well plates pre-treated with $0.01 \%$ solution of poly-lysine in phosphate-buffered saline (PBS), and cultivated overnight to $80-100 \%$ confluence.

Radioreceptor-assay (Nägler et al., 2010) The cell monolayers were washed three times with cold PBS buffer. All further steps were performed on ice. The cells were first equilibrated for $30 \mathrm{~min}$ with $200 \mu \mathrm{l}$ of incubation buffer (40 mM PIPES, $100 \mathrm{~mm} \mathrm{NaCl}$, $5 \mathrm{~mm} \mathrm{KCl}, 0.1 \%$ glucose, $0.05 \% \mathrm{BSA}, 2 \mathrm{mM} \mathrm{CaCl}_{2}$ and $1 \mathrm{~mm}$ $\mathrm{MgCl}_{2}, \mathrm{pH}$ 7.4), containing peptidase inhibitor mixtures: $2 \mathrm{~mm}$ bacitracin, $0.8 \mathrm{~mm}$ 1,10-phenanthroline and $100 \mu \mathrm{M}$ captopril for B2 receptor-bearing cells or $0.5 \mathrm{~mm}$ bacitracin, $0.02 \mathrm{~mm} 1,10$-phenanthroline and $100 \mu \mathrm{M}$ captopril for B1 receptor-containing cells. Then the cells were incubated for 90 min with $100 \mu l$ of the buffer containing $1 \mathrm{~nm}\left[{ }^{3} \mathrm{H}\right]$ des-Arg ${ }^{10}$-kallidin (Perkin-Elmer, Waltham, MA, USA) (for B1 receptor-based assay) or $2 \mathrm{nM}\left[{ }^{3} \mathrm{H}\right]$ bradykinin (Perkin-Elmer) (for $\mathrm{B} 2$ receptor-based assay) and 10- to 20 -fold diluted samples from HK degradation experiments. The calibration curves were made with DAKD or bradykinin solutions of concentrations in a range of $0.01-30 \mathrm{nM}$. The reaction was stopped by washing the cells with PBS (four times) and incubation for $30 \mathrm{~min}$ with $200 \mu \mathrm{l}$ of a solution of $0.5 \mathrm{M} \mathrm{NaCl}$ and $0.2 \mathrm{M}$ acetic acid, $\mathrm{pH}$ 2.7 as described previously (Faussner et al., 2005). The supernatant containing the dissociated radioligand was transferred to $2.5 \mathrm{ml}$ of scintillation fluid (Ultima Gold ${ }^{\mathrm{TM}}$, Perkin-Elmer) and the radioactivity was measured in a beta-counter (Wallace 1412, LKB, Uppsala, Sweden). Non-specific binding was determined in the presence of $1 \mu \mathrm{M}$ of respective unlabeled ligand.

Data analysis All points in the figures represent the mean \pm SE of at least three experiments done in duplicate. In all receptor binding studies the competition analysis for one-site model was performed using GraphPad Prism computer software.

\section{Acknowledgments}

This work was supported in parts by the grant No. 2P04C 03529 from the Ministry of Science and Higher Education (Poland) and the statutory funds of the Faculty of Biochemistry, Biophysics and Biotechnology of the Jagiellonian University. The Faculty of Biochemistry, Biophysics and Biotechnology of the Jagiellonian University is a beneficiary of the structural funds from the European Union (grant No. POIG.02.01.00-12-064/08 - 'Molecular biotechnology for health').

\section{References}

Anson, M.L. (1938). The estimation of pepsin, trypsin, papain, and cathepsin with hemoglobin. J. Gen. Physiol. 22, 79-89.

Barbasz, A. and Kozik, A. (2009). The assembly and activation of kinin-forming systems on the surface of human U-937 macrophage-like cells. Biol. Chem. 390, 269-275.

Barbasz, A, Guevara-Lora, I., Rapala-Kozik, M., and Kozik, A. (2008). Kininogen binding to the surfaces of macrophages. Int. Immunopharmacol. 8, 211-216.

Ben Nasr, A., Herwald, H., Müller-Esterl, W., and Björck, L. (1995). Human kininogens interact with $M$ protein, a bacterial surface protein and virulence determinant. Biochem. J. 305, 173-180.
Ben Nasr, A., Herwald, H., Sjöbring, U., Renne, T., Müller-Esterl, W., and Björck, L. (1997). Absorption of kininogen from human plasma by Streptococcus pyogenes followed by the release of bradykinin. Biochem. J. 326, 657-660.

Bengtson, S.H, Phagoo, S.B., Norrby-Teglund, A., Påhlman, L., Mörgelin, M., Zuraw, B.L., Leeb-Lundberg, L.M., and Herwald, H. (2006). Kinin receptor expression during Staphylococcus aureus infection. Blood 108, 2055-2063.

Bergmann, S. and Hammerschmidt, S. (2007). Fibrinolysis and host response in bacterial infections. Thromb. Haemost. 98, 512-520.

Blum, H., Beier, H., and Gross, H.J. (1987). Improved silver staining of plant proteins, RNA and DNA in polyacrylamide gels. Electrophoresis 8, 93-99.

Boskey, E.R., Telsch, K.M., Whaley, K.J., Moench, T.R., and Cone, R.A. (1999). Acid production by vaginal flora in vitro is consistent with the rate and extent of vaginal acidification. Infect. Immun. 67, 5170-5175.

Bradford, M.M. (1976). A rapid and sensitive method for the quantitation of microgram quantities of protein utilizing the principle of protein-dye binding, Anal. Biochem. 72, 248-254.

Cheng, M.F., Yang, Y.L., Yao, T.J., Lin, C.Y., Liu, J.S., Tang, R.B., Yu, K.W., Fan, Y.H., Hsieh, K.S., Ho, M., et al. (2005). Risk factors for fatal candidemia caused by Candida albicans and non-albicans Candida species. BMC Infect. Dis. 5, 22-27.

Colman, R.W. and Schmaier, A.H. (1997). Contact system: a vascular biology modulator with anticoagulant, profibrinolytic, antiadhesive, and proinflammatory attributes. Blood 90, 3819-3843.

De Bernardis, F., Mühlschlege, F.A., Cassone, A., and Fonzi, W.A. (1998). The $\mathrm{pH}$ of the host niche controls gene expression in and virulence of Candida albicans. Infect. Immun. 66, 33173325 .

Dean, D.A. and Burchard, K.W. (1998). Surgical perspective on invasive Candida infections. World J. Surg. 22, 127-134.

Faussner, A., Bauer, A., Kalatskaya, I., Schüssler, S., Seidl, C., Proud, D., and Jochum, M. (2005). The role of helix 8 and of the cytosolic $\mathrm{C}$-termini in the internalization and signal transduction of $\mathrm{B}_{1}$ and $\mathrm{B}_{2}$ bradykinin receptors. FEBS J. 272, 129-40.

Felk, A., Kretschmar, M., Albrecht, A., Schaller, M., Beinhauer, S., Nichterlein, T., Sanglard, D., Korting, H.C., Schäfer, W., and Hube, B. (2002). Candida albicans hyphal formation and the expression of the Efg1-regulated proteinases Sap4 to Sap6 are required for the invasion of parenchymal organs. Infect. Immun. 70, 3689-3700.

Frick, I.M., Bjorck, L., and Herwald, H. (2007). The dual role of the contact system in bacterial infectious disease. Thromb. Haemost. 98, 497-502.

Hack, C.E. and Colman, W.R. (1999). The role of the contact system in the pathogenesis of septic shock. Sepsis 3, 111-118.

Herwald, H., Collin, M., Muller-Esterl, W., and Bjorck L. (1996). Streptococcal cysteine proteinase releases kinins: a novel virulence mechanism. J. Exp. Med. 184, 665-673.

Herwald, H., Mörgelin, M., Olsén, A., Rhen, M., Dahlbäck, B., Müller-Esterl, W., and Björck, L. (1998). Activation of the contact-phase system on bacterial surfaces - a clue to serious complications in infectious diseases. Nat. Med. 4, 298-302.

Herwald, H., Morgelin, M., and Bjorck, L. (2003). Contact activation by pathogenic bacteria: a virulence mechanism contributing to the pathophysiology of sepsis. Scand. J. Infect. Dis. 36, 604-607.

Hrušková-Heidingsfeldová, O., Dostál, J., Majer, F., Havlíková, J., Hradilek, M., and Pichová, I. (2009). Two aspartic proteinases secreted by the pathogenic yeast Candida parapsilosis differ in 
expression pattern and catalytic properties. Biol. Chem. 390, 259-268.

Imamura, T., Potempa, J., and Travis, J. (2004). Activation of the kallikrein-kinin system and release of new kinins through alternative cleavage of kininogens by microbial and human cell proteinases. Biol. Chem. 385, 989-996.

Imamura, T., Tanase, S., Szmyd, G., Kozik, A., Travis, J., and Potempa, J. (2005). Induction of vascular leakage through release of bradykinin and a novel kinin by cysteine proteinases from Staphylococcus aureus. J. Exp. Med. 201, 1669-1676.

Imamura, T., Kobayashi, H., Khan, R., Nitta, H., and Okamoto, K. (2007). Induction of vascular leakage and blood pressure lowering through kinin release by a serine proteinase from Aeromonas sobria. J. Immunol. 177, 8723-8729.

Johnson, D.A., Salvesen, G., Brown, M.A., and Barrett, A.J, (1987). Rapid isolation of human kininogens. Thromb. Res. 48, 187-193.

Joseph, K. and Kaplan, A.P. (2005). Formation of bradykinin: a major contributor to the innate inflammatory response. Adv. Immunol. 86, 159-208.

Kaminishi, H., Tanaka, M., Cho, T., Maeda, H., and Hagihara, Y. (1990). Activation of the plasma kallikrein-kinin system by Candida albicans proteinase. Infect. Immun. 58, 2139-2143.

Kaplan, A.P., Joseph, K., and Silverberg, M. (2002). Pathways for bradykinin formation and inflammatory disease. J. Allergy Clin. Immunol. 109, 195-209.

Karkowska-Kuleta, J., Rapala-Kozik, M., and Kozik, A. (2009). Fungi pathogenic to humans: molecular bases of virulence of Candida albicans, Cryptococcus neoformans and Aspergillus fumigatus. Acta Biochim. Pol. 56, 211-224.

Karkowska-Kuleta, J., Kozik, A., and Rapala-Kozik M. (2010). Binding and activation of human plasma kinin-forming system on the cell walls of Candida albicans and Candida tropicalis. Biol. Chem. 391, 97-103.

Koelsch, G., Tang, J., Loy, J.A., Monod, M., Jackson, K., Foundling, S.I., and Lin, X. (2000). Enzymatic characteristics of secreted aspartic proteases of Candida albicans. Biochim. Biophys. Acta 1480, 117-131.

Laemmli, U.K. (1970). Cleavage of structural proteins during the assembly of the head of bacteriophage T4. Nature 227, 680-685.

Maeda, H. and Yamamoto, T. (1996). Pathogenic mechanisms induced by microbial proteases in microbial infections. Biol. Chem. Hoppe-Seyler 377, 217-226.

Maruo, K., Akaike, T., Ono, T., and Maeda, H. (1998). Involvement of bradykinin generation in intravascular dissemination of Vibrio vulnificus and prevention of invasion by a bradykinin antagonist. Infect. Immun. 66, 866-869.

Matsudaira, P. (1987). Sequence from picomole quantities of proteins electroblotted onto polyvinylidene difluoride membranes. J. Biol. Chem. 262, 10035-10038.

Mattsson, E., Herwald, H., Cramer, H., Persson, K., Sjöbring, U., and Björck, L. (2001). Staphylococcus aureus induces release of bradykinin in human plasma. Inf. Immun. 69, 3877-3882.

Mavor, A.L., Thewes, S., and Hube, B. (2005). Systemic fungal infections caused by Candida species: epidemiology, infection process and virulence attributes. Curr. Drug Targets 6, 863-874.

Miyoshi, S., Watanabe, H., Kawase, T., Yamada, H., and Shinoda, S. (2004). Generation of active fragments from human zymogens in the bradykinin-generating cascade by extracellular proteases from Vibrio vulnificus and V. parahaemolyticus. Toxicon 44, 887-893.

Molla, A., Yamamoto, T., Akaike, T., Miyoshin, S., and Maeda, H. (1989). Activation of Hageman factor and prekallikrein and gen- eration of kinin by various microbial proteinases. J. Biol. Chem. 264, 10589-10594.

Nägler, D.K., Kraus, S., Feierler, J., Mentele, R., Lottspeich, F., Jochum, M., and Faussner, A. (2010). A cysteine-type carboxypeptidase, cathepsin $\mathrm{X}$, generates peptide receptor agonists. Int. Immunopharmacol. 10, 134-139.

Naglik, J.R., Challacombe, S.J., and Hube, B. (2003). Candida albicans secreted aspartyl proteinases in virulence and pathogenesis. Microbiol. Mol. Biol. Rev. 67, 400-428.

Naglik, J., Albrecht, A., Bader, O., and Hube, B. (2004). Candida albicans proteinases and host/pathogen interactions. Cell Microbiol. 6, 915-926.

Perfect, J.R. and Casadevall, A. (2006). Fungal molecular pathogenesis: what can it do and why do we need it? In: Molecular Principles of Fungal Pathogenesis, J. Heitman, S.G. Filler, J.E. Edwards Jr. and A.P. Mitchell, eds. (Washington, DC, USA: ASM Press), pp. 3-11.

Phagoo, S.B., Reddi, K., Silvallana, B.J., Leeb-Lundberg, L.M., and Warburton, D. (2005). Infection-induced kinin B1 receptors in human pulmonary fibroblasts: role of intact pathogens and p38 mitogen-activated protein kinase-dependent signaling. J. Pharmacol. Exp. Ther. 313, 1231-1238.

Potempa, J., Banbula, A., and Travis, J. (2000). Role of bacterial proteinases in matrix destruction and modulation of host responses. Periodontology 24,153-192.

Rapala-Kozik, M., Karkowska, J., Jacher, A., Golda, A., Barbasz, A., Guevara-Lora, I., and Kozik, A. (2008). Kininogen adsorption to the cell surface of Candida spp. Int. Immunopharmacol. 8, 237-241.

Richardson, M.D. (2005). Changing patterns and trends in systemic fungal infections. J. Antimicrob. Chemother. 56, 5-11.

Rodier, M.H., el Moudni, B., Kauffmann-Lacroix, C., Daniault, G., and Jacquemin, J.L. (1999). A Candida albicans metallopeptidase degrades constitutive proteins of extracellular matrix. FEMS Microbiol. Lett. 177, 205-210.

Souza dos Santos, L.A., Miller de Carvalho, I., Alcantara da Silva, B., Portela, M.B., Sales Alviano, C., and de Araujo Soares, R.M. (2006). Secretion of serine peptidase by a clinical strain of Candida albicans: influence of growth conditions and cleavage of human serum proteins and extracellular matrix components. FEMS Immunol. Med. Microbiol. 46, 209-220.

Stadnicki, A., Pastucha, E., Nowaczyk, G., Mazurek, U., Plewka, D., Machnik, G., Wilczok, T., and Colman, R.W. (2005). Immunolocalization and expression of kinin $\mathrm{B} 1 \mathrm{R}$ and $\mathrm{B} 2 \mathrm{R}$ receptors in human inflammatory bowel disease. Am. J. Physiol. Gastrointest. Liver Physiol. 289, G361-G366.

Staib, P., Kretschmar, M., Nichterlein, T., Hof, H., and Morschhauser, J. (2000). Differential activation of a Candida albicans virulence gene family during infection. Proc. Natl. Acad. Sci. USA 97, 6102-6107.

Tapper, H. and Herwald, H. (2000). Modulation of hemostatic mechanisms in bacterial infectious diseases. Blood 96, 2329-2337.

White, T.C. and Agabian N. (1995). Candida albicans secreted aspartyl proteinases: isoenzyme pattern is determined by cell type, and levels are determined by environmental factors. J. Bacteriol. 177, 5215-5221.

Zubakova, R., Gille, A., Faussner, A., and Hilgenfeldt, U. (2008). $\mathrm{Ca}^{2+}$ signalling of kinins in cells expressing rat, mouse and human B1/B2-receptor. Int. Immunopharmacol. 8, 276-281.

Received January 1, 2010; accepted March 26, 2010 